\title{
Designing, Manufacturing, and Testing a Voice-controlled Intelligent Drawer
}

\author{
Yao-Tsung Yang, ${ }^{1}$ Tan-Chih Chang, ${ }^{2}$ and Feng-Min Lai ${ }^{*}$ \\ ${ }^{1}$ Bachelor Program for Design and Materials for Medical Equipment and Devices, Da-Yeh University \\ No. 168, University Rd., Dacun, Changhua 515006, Taiwan (R.O.C.) \\ ${ }^{2}$ Department of Mechanical and Automation Engineering, Da-Yeh University \\ No. 168, University Rd., Dacun, Changhua 515006, Taiwan (R.O.C.)
}

(Received July 6, 2021; accepted November 16, 2021)

Keywords: smart, carbon fiber, light-weight, voice control, sensor, Arduino

In this study, a voice control model was assembled using Arduino UNO and LD3320 sensor modules, and this model was then used to create the voice control system for use in a smart drawer that could improve the convenience of daily life. We enhanced the receiving function of the voice control system to check the safety of the smart drawer, to reduce the error rate of speech recognition, and to raise the precision of supportive action. We developed carbon/carbon nanotubes (CNTs)/epoxy parts and one smart drawer with carbon fibers woven into cloth with light weight, high strength, and high tenacity. The carbon-fiber-woven cloth combined with CNTs/epoxy was stronger than those previously used in auxiliary appliances and achieved greater lightness and strength. We combined the carbon-fiber-woven cloth and CNTs/epoxy with different weight percentages of CNTs $(0.5,1$, and $2 \mathrm{wt} \%)$ in epoxy, and manufactured test pieces of carbon/CNTs/epoxy samples with different amounts of CNTs and performed tensile, threepoint bending, and impulse tests. Finally, to reduce the weight of the drawer, we used carbon/ CNTs/epoxy components comprising the carbon-fiber-woven cloth and $1 \mathrm{wt} \% \mathrm{CNTs} /$ epoxy. We created a smart drawer with voice control in this study; the drawer's switch can be controlled using voice recognition and remote control. The smart drawer is composed of a light-weight, high-strength, and high-tenacity carbon fiber/epoxy composite material with $1 \mathrm{wt} \% \mathrm{CNTs}$. The carbon/CNTs/epoxy smart drawer has the advantages of light weight, durability, controllability, and signal stability, making it ideal for use in care devices. The LD3320 sensor board combined with Arduino UNO successfully used the sound to drive the motor of the smart drawer, and the switch action can be performed.

\section{Introduction}

When a voice control model is combined with an auxiliary medical appliance, the convenience of the appliance may be increased. The growth of the global aged population is the key impetus behind the growth of the medical mobility auxiliary appliance market. Carbon fiber composite material has many advantages such as light weight, high rigidity, high strength, superior design freedom, and corrosion resistance. ${ }^{(1)}$ However, the demand for carbon fibers is *Corresponding author: e-mail: fengmin@mail.dyu.edu.tw https://doi.org/10.18494/SAM.2021.3534 
stepping toward a positive and stable high growth trend, and the supply side will also move forward hand in hand. ${ }^{(2)}$ Arduino UNO, which can be used to develop interactive objects, handle a large amount of switch or sensor inputs, and control other physical outputs, ${ }^{(3)}$ was adopted to control the switch of a smart drawer. The LD3320 sensor received the voice to drive the motor of the smart drawer, and the switch action can be performed.

\section{Materials and Methods}

In this study, we used a carbon fiber plank and bent steel to create the product design of the smart drawer and used Arduino UNO and LD3320 modules to assemble the voice control system with the program written in the Romanization system (as shown in Fig. 1). To fabricate the drawer, we adopted the hand layup method ${ }^{(4)}$ to prepare the carbon fiber plank and performed tensile, three-point bending, and shock tests. ${ }^{(5,6)}$

\subsection{Preparation of materials}

The materials were prepared by a hand layup approach using carbon-fiber-woven cloth and carbon nanotubes (CNTs)/epoxy. We first mixed $1 \mathrm{wt} \%$ CNTs (CF182C, Advanced Nanopower Inc.) and epoxy (P859-1, Hong Guan R\&D Co.) into a CNTs/epoxy paste. Then, the front surface of the carbon-fiber-woven cloth (CFK680) was coated with the CNTs/epoxy paste and dried in an oven at $130{ }^{\circ} \mathrm{C}$ for $120 \mathrm{~min}$. The main body of the smart drawer comprises carbon fiber parts bent to form a right angle and a carbon fiber plank ${ }^{(7)}$ (Fig. 2). First, we cut the carbon-fiberwoven cloth and release the cloth into appropriate sizes. ${ }^{(8)}$ Second, two bent sheets of steel are clad with the released paper and the carbon-fiber-woven cloth coated with the $1 \mathrm{wt} \% \mathrm{CNTs} /$ epoxy paste is fixed between the two bent sheets of steel. This ensemble is placed in an oven for drying at $130{ }^{\circ} \mathrm{C}$ for $90 \mathrm{~min}$ (Fig. 3).

\subsection{Carbon/CNTs/epoxy samples and mechanical property testing}

Samples of carbon/CNTs/epoxy were prepared by coating the front surface of the carbonfiber-woven cloth with CNTs/epoxy pastes containing 0.5, 1 , and $1.5 \mathrm{wt} \% \mathrm{CNTs}$ for use in various tests of the mechanical properties.

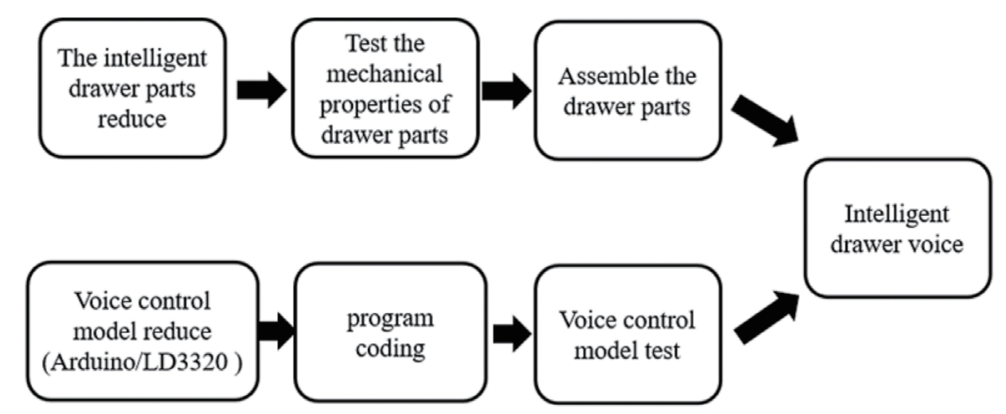

Fig. 1. Fabrication processes of intelligent drawer. 


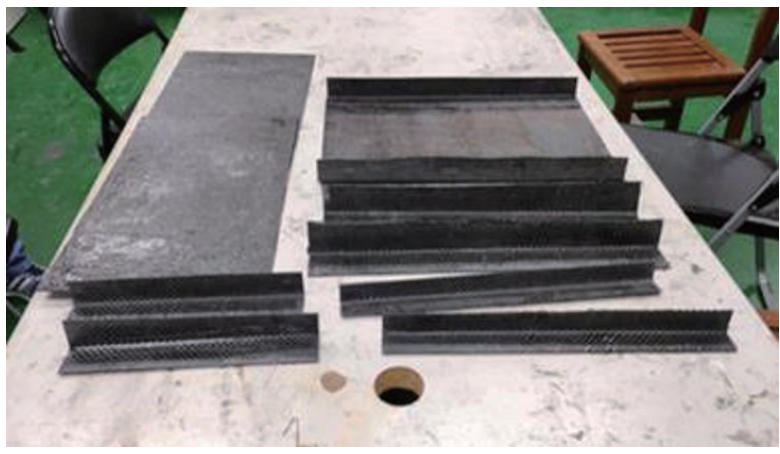

Fig. 2. (Color online) Parts of the intelligent drawer.

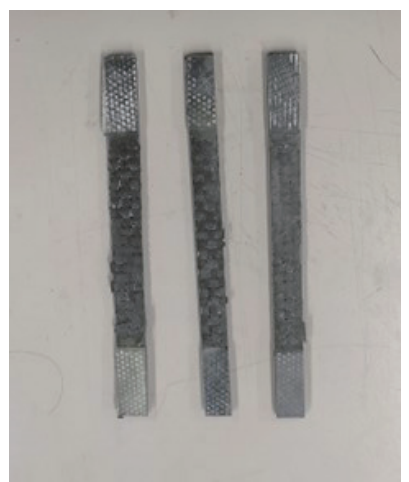

Fig. 4. (Color online) Samples for tensile testing.

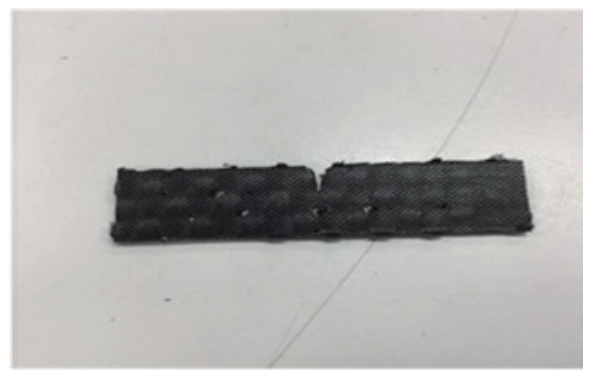

(a)

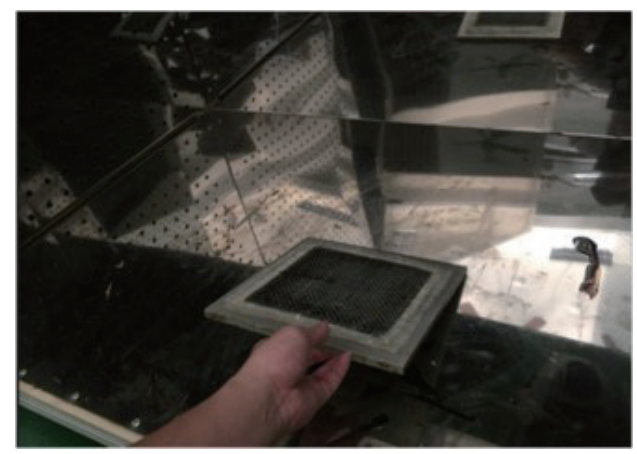

Fig. 3. (Color online) Drying the parts of the intelligent drawer in an oven.

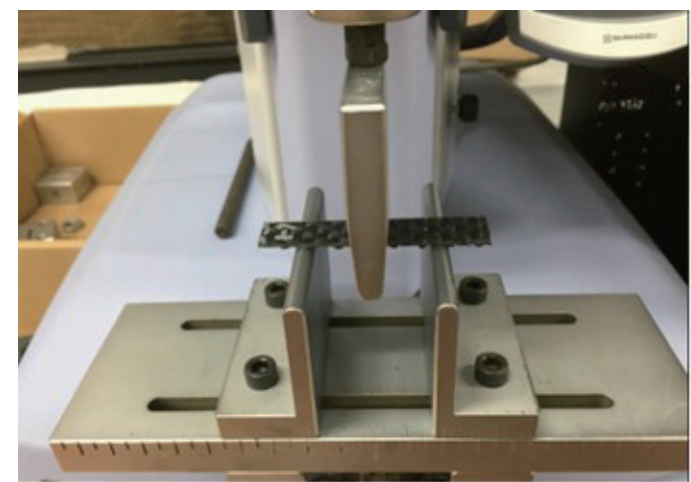

Fig. 5. (Color online) Setup of three-point bending test.

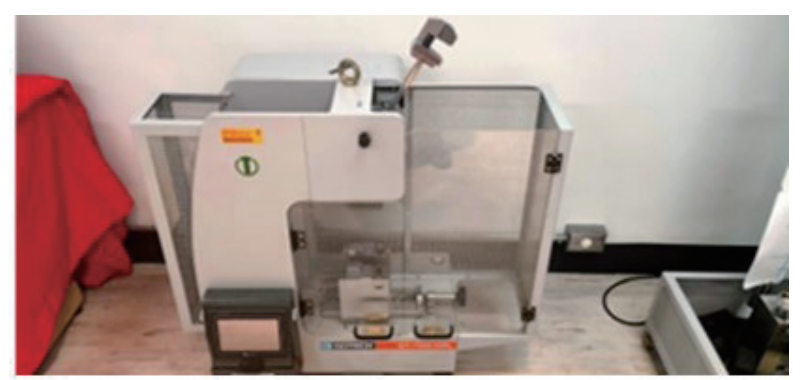

(b)

Fig. 6. (Color online) (a) Impulse test sample with notch and (b) impulse test machine.

The tensile test sample size was $140 \times 10 \times 5 \mathrm{~mm}^{3}$ (Fig. 4), the tensile gage length was $40 \mathrm{~mm}$, and the stretching rate was $1 \mathrm{~mm} / \mathrm{min}$. The three-point bending test (Fig. 5) was performed in accordance with the ASTM D790-10 test standard; the bending test rate was $1 \mathrm{~mm} /$ min and the bending test sample size was $80 \times 12.85 \times 3.2 \mathrm{~mm}^{3}$. The impulse test sample for the impact test had a V-shaped notch with a depth of $0.25 \mathrm{R} \pm 0.5 \mathrm{~mm}$ (Fig. 6), and the sample size was $63.5 \times 12.85 \times 3.2 \mathrm{~mm}^{3}$. Each test was conducted five times. 


\subsection{Voice control program coding and controller assembly}

We used Arduino UNO and LD3320 voice recognition modules to build a voice control system (Fig. 7). Arduino IDE prescribed the program in a laptop computer and combined the Arduino panel and LD3320 module.

\section{Results and Discussion}

\subsection{Results of smart drawer mechanical property testing}

To ensure sufficient strength for the smart drawer, we performed tensile, three-point bending, and impact tests. The test samples prepared using the carbon-fiber-woven cloth and CNTs/epoxy pastes with $0,0.5,1$, and $1.5 \mathrm{wt} \%$ CNTs. The results of the tensile, three-point bending, and impact tests are shown in Tables 1, 2, and 3, respectively. All test results indicated the combination of $1 \mathrm{wt} \%$ CNTs/epoxy paste and carbon-fiber-woven cloth to be the best for the smart drawer.

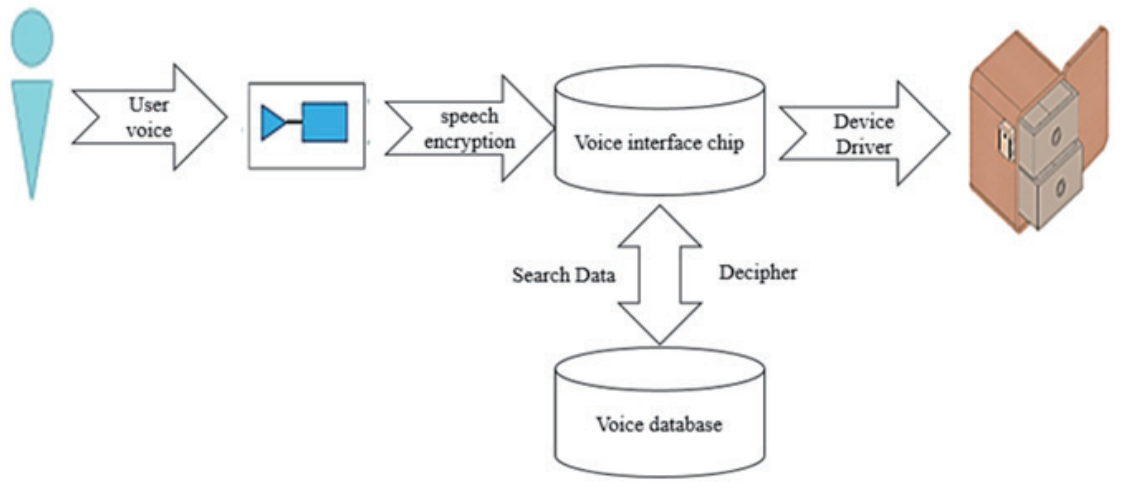

Fig. 7. (Color online) Voice control system.

Table 1

Tensile test results.

\begin{tabular}{lcccc}
\hline $\begin{array}{l}\text { Amount of CNTs } \\
(\mathrm{wt} \%)\end{array}$ & $\begin{array}{c}\text { Young's coefficient } \\
(\mathrm{GPa})\end{array}$ & $\begin{array}{c}\text { Breaking stress } \\
(\mathrm{MPa})\end{array}$ & $\begin{array}{c}\text { Density } \\
\left(\mathrm{kg} / \mathrm{m}^{3}\right)\end{array}$ & $\begin{array}{c}\text { Specific rigidity } \\
(\mathrm{kN} \cdot \mathrm{m} / \mathrm{kg})\end{array}$ \\
\hline 0 & 7.106 & 356.98 & 1602 & 4.435 \\
0.5 & 8.055 & 381.66 & 1721 & 4.680 \\
1 & 9.586 & 426.19 & 1921 & 4.990 \\
1.5 & 8.951 & 372.33 & 1845 & 4.851 \\
\hline
\end{tabular}

Table 2

Three-point bending test results.

\begin{tabular}{lccc}
\hline $\begin{array}{l}\text { Amount of CNTs } \\
(\mathrm{wt} \%)\end{array}$ & $\begin{array}{c}\text { Young's coefficient } \\
(\mathrm{GPa})\end{array}$ & $\begin{array}{c}\text { Density } \\
\left(\mathrm{kg} / \mathrm{m}^{3}\right)\end{array}$ & $\begin{array}{c}\text { Specific rigidity } \\
(\mathrm{kN} \cdot \mathrm{m} / \mathrm{kg})\end{array}$ \\
\hline 0 & 3.645 & 1432 & 2.545 \\
0.5 & 4.015 & 1359 & 2.954 \\
1 & 4.460 & 1472 & 3.029 \\
1.5 & 3.957 & 1399 & 2.828 \\
\hline
\end{tabular}


Table 3

Impact test results.

\begin{tabular}{lccc}
\hline $\begin{array}{l}\text { Amount of CNTs } \\
(\mathrm{wt} \%)\end{array}$ & $\begin{array}{c}\text { Impact strength } \\
(\mathrm{J} / \mathrm{m})\end{array}$ & $\begin{array}{c}\text { Density } \\
\left(\mathrm{kg} / \mathrm{m}^{3}\right)\end{array}$ & $\begin{array}{c}\text { Specific strength } \\
\left(10^{-3} \mathrm{~J} \cdot \mathrm{m}^{2} / \mathrm{kg}\right)\end{array}$ \\
\hline 0 & 188.75 & 1280 & 147.460 \\
0.5 & 198.22 & 1326 & 149.487 \\
1 & 221.86 & 1446 & 153.43 \\
1.5 & 210.54 & 1419 & 148.37 \\
\hline
\end{tabular}

\subsection{Voice control test for the smart drawer}

The voice control module was used to control the driving motor to move the drawer, which could make it easier for the elderly to manipulate the drawer (Fig. 8). Arduino UNO and LD3320 sensor modules were used to build a voice control model. The smart drawer was tested by a number of people and found to respond appropriately in all cases (Fig. 9). The first set of voice commands had four words, and the following instructions cannot be operated without the first set of commands. In the second command, the spoken word "high" was the switch to open the circuit.
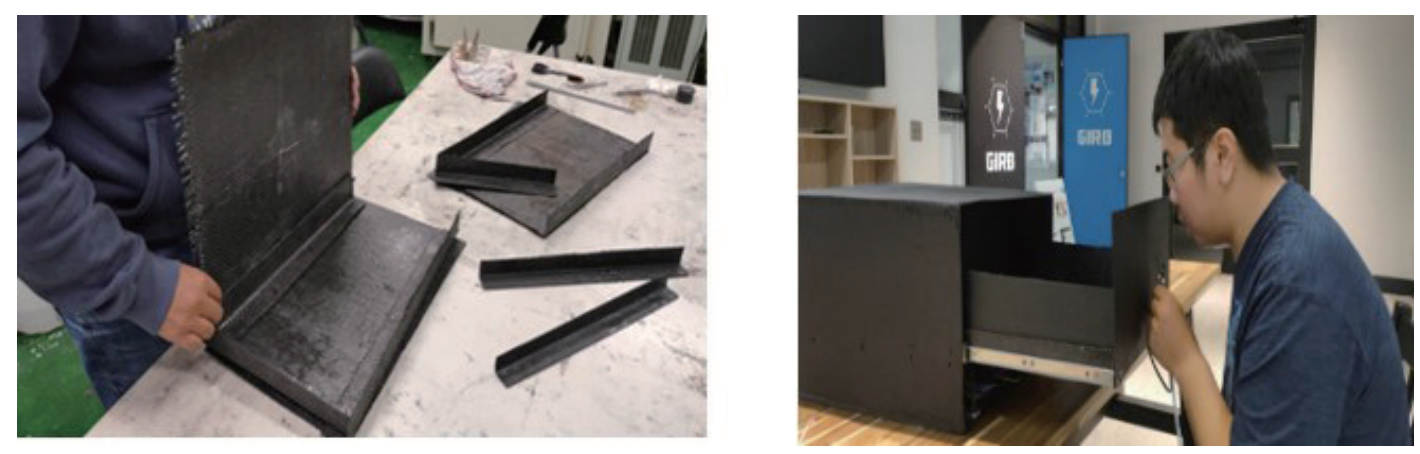

Fig. 8. (Color online) Construction of the smart drawer and the finished product.
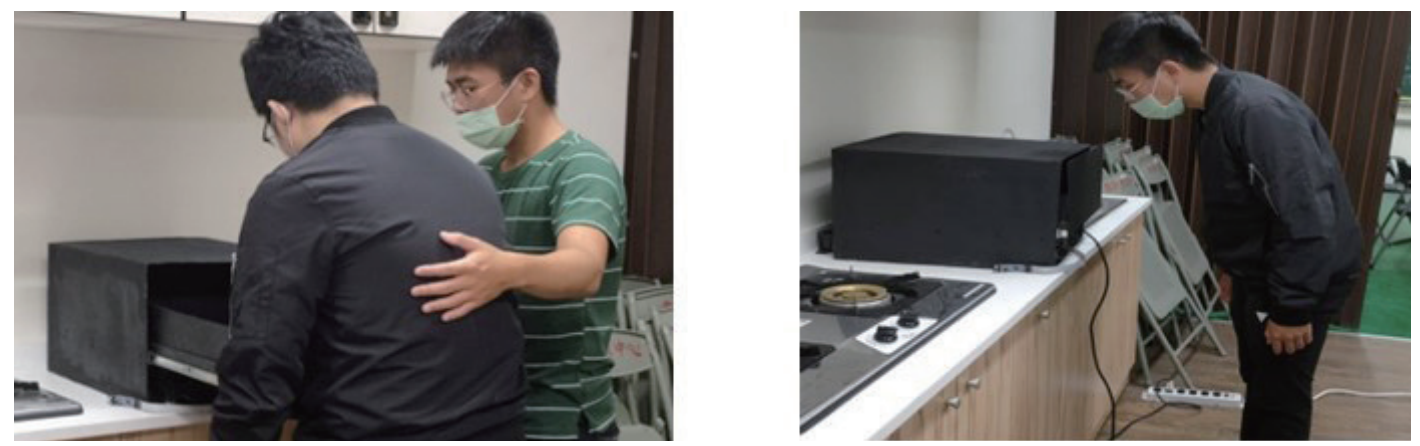

Fig. 9. (Color online) Different people test the switch model. 


\section{Conclusions}

1. The voice control model in this study comprised Arduino UNO and LD3320 sensor modules, and the program was written in the Romanization system.

2. The LD3320 sensor board combined with Arduino UNO successfully used the sound to drive the motor of the smart drawer, and the switch action can be performed.

3. In the tensile test, the maximum fracture stress was $367.58 \mathrm{MPa}$ and the specific rigidity was $4.435 \mathrm{kN} \cdot \mathrm{m} / \mathrm{kg}$.

4. The bending performance of the carbon fiber sample was indicated by the results of the threepoint bending test; Young's coefficient was $4.46 \mathrm{GPa}$ for the carbon/1 wt $\% \mathrm{CNTs} / \mathrm{epoxy}$ paste sample.

5. In the impact test result, the impact strength reached $221.86 \mathrm{~J} / \mathrm{m}$. Overall, the combinations of carbon fiber and CNTs/epoxy pastes that we used had high strength and high impact strength features.

6. The smart drawer made of carbon/CNTs/epoxy had light weight, good strength, good controllability, and signal stability, making it promising as a care aid.

\section{References}

1 J. J. J. Samuel, R. Ramadoss, K. N. Gunasekaran, K. Logesh, S. J. P. Gnanaraj, and A. A. Munaf: Materials Today: Proc. 47 (2021) 4438-4443. https://www.sciencedirect.com/science/article/pii/ S2214785321038980?casa token=YTX6pjGL20oAAAAA:eWLagvTc7Bceeoxr4JZP8pgqzTE9YVMq b5M0b8EN7jjs5IAvLOD4Mxf3EksNtuVG7oyGLKduA

2 P. Krishnan, M. S. A. Majid, M. Afendi, A. G. Gibson, and H. F. A. Marzuki: Mater. Des. 88 (2015) 196. https:// www.sciencedirect.com/science/article/abs/pii/S0264127515304020

3 H. K. Kondaveeti, N. K. Kumaravelu, S. D. Vanambathina, S. E. Mathe, and S. Vappangi: Comput. Sci. Rev. 40 (2021) 100364. https://www.sciencedirect.com/science/article/abs/pii/S1574013721000046

4 D. Carlile, D. Leach, D. Moore, and N. Zahlan: Mechanical Properties of the Carbon Fiber/PEEK Composite APC-2/AS-4 for Structural Applications (ASTM STP 1044, 1989) p. 1. https://www.astm.org/DIGITAL LIBRARY/STP/PAGES/STP24603S.htm

5 Z. Maekawa, H. Hamada, K. Lee, and T. Kitagawa: Composites 25 (1994) 37. https://www.sciencedirect.com/ science/article/abs/pii/0010436194900655

6 M. Lossie: Production Oriented Design of Filament Wound Composites (1990) 33-59. https://www. semanticscholar.org/paper/Production-oriented-design-of-filemant-wound-Lossie/a99669c5ce7f53e9119eebebc 03670f177a50fd7\#related-papers

7 S. T. Peters, W. D. Humphrey, and R. F. Foral: Filament Winding, Composite Structure Fabrication (1991). https://www.osti.gov/biblio/5642746

8 Y. M. Tranpol and A. I. Beil: Handbook of Composites 4 (Elsevier Science Publishers B. V., 1983) pp. 45-108. https://scholar.google.com/scholar lookup?hl=en\&publication year=1983\&pages=45-108\&author=+Tarnopol

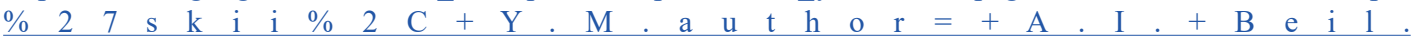
author $=+$ A. + Kellyauthor $=+$ S. + T. + Mileiko $\&$ title $=$ Problems + of + the + Mechanics + of + Composite + Winding $\% 2 \mathrm{C}$ $\% 22+$ Chapter + II + in + Handbook + of + Composites $\% 2 C+$ Vol. +4 -Fabrication + of + Composites 


\section{About the Authors}

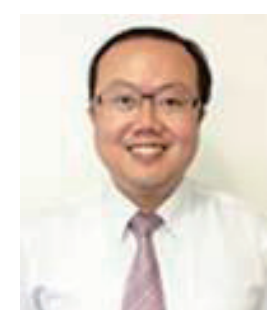

Yao-Tsung Yang received his M.S. and Ph.D. degrees from Da-Yeh University, Taiwan, in 1993 and 1997, respectively. Since 2017, he has been an associate professor at Da-Yeh University, Taiwan. His main areas of interest include dental implantology, prosthodontology, 3D printing, the manufacture of composite materials, tensile test research, control, and computer graphics.

(p2410@mail.dyu.edu.tw)

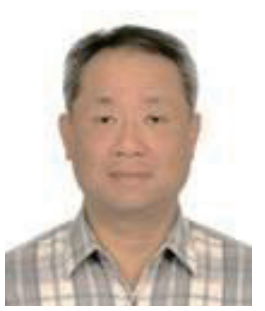

Tan-Chih Chang received his B.S. degree from Feng Chia University, Taiwan, in 1986 and his M.S. degree from Feng Chia University, Department of Civil Engineering, Taiwan, in 1989. He is currently a Ph.D. student at DaYeh University. Since 2018, he has been a researcher at Da-Yeh University, Taiwan. His research interests include 3D printing, the manufacture of composite materials, tensile testing in carbon fiber research, voice control, and computer graphics. (hiciv@ms43.hinet.net)

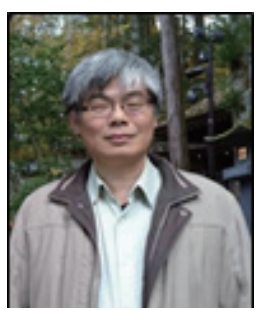

Feng-Min Lai received his B.S. degree from Chinese Culture University, Taiwan, in 1991 and his M.S. and Ph.D. degrees from the National Chiao Tung University, Taiwan, in 1993 and 1997, respectively. From 2002 to 2016, he was an associate professor at Da-Yeh University, Taiwan. Since 2017, he has been a professor at Da-Yeh University. His research interests are in composite materials, computer graphics, and medical aid development.

(fengmin@mail.dyu.edu.tw) 